\title{
In Perfect Harmony: Synchronizing the Self to Activated Social Categories
}

\author{
Kerry Kawakami and Curtis E. Phills \\ York University
}

\author{
Daniel Simard, Jeannette Pontiero, Amy Brnjas, \\ Beenish Khan, and Jennifer Mills \\ York University
}

\author{
Anthony G. Greenwald \\ University of Washington
}

\author{
John F. Dovidio \\ Yale University
}

\begin{abstract}
The self-concept is one of the main organizing constructs in the behavioral sciences because it influences how people interpret their environment, the choices they make, whether and how they initiate action, and the pursuit of specific goals. Because belonging to social groups and feeling interconnected is critical to human survival, the authors propose that people spontaneously change their working self-concept so that they are more similar to salient social categories. Specifically, 4 studies investigated whether activating a variety of social categories (i.e., jocks, hippies, the overweight, Blacks, and Asians) increased associations between the self and the target category. Whereas Studies 1 and 2 focused on associations between stereotypic traits and the self, Studies 3 and 4 examined self-perceptions and selfcategorizations, respectively. The results provide consistent evidence that following social category priming, people synchronized the self to the activated category. Furthermore, the findings indicate that factors that influence category activation, such as social goals, and factors that induce a focus on the interconnectedness of the self, such as an interdependent vs. independent self-construal, can impact this process. The implications of changes to the working self-concept for intergroup relations are discussed.
\end{abstract}

Keywords: implicit biases, automatic processes, self-other overlap, intergroup relations

The self-concept is one of the main organizing constructs in the behavioral and social sciences (Cooley, 1902; James, 1890; Leary \& Tangney, 2003; Mead, 1934). It is a higher order organizing schema that fundamentally determines the specific attitudes, behaviors, and emotions that people will express in a given situation. Although the self-concept is the sum total of what people believe and know about themselves (Baumeister, 1999), at any given moment only a small part of this information is salient (Showers \& Zeigler-Hill, 2003). This subset of retrieved associations, the working self-concept, contains the knowledge that will be brought to bear in any specific context (Cantor, Markus, Niedenthal, \& Nurius, 1986; Markus \& Kunda, 1986; Markus \& Nurius, 1986) and influences how people interpret their environment, the choices they make, whether and how they initiate action, and their pursuit of specific goals (Greenwald \& Banaji, 1995; Greenwald, Pickrell, \& Farnham, 2002; Kunda, 1999; Showers \& Zeigler-Hill, 2003).

This article was published Online First November 7, 2011.

Kerry Kawakami, Curtis E. Phills, Daniel Simard, Jeannette Pontiero, Amy Brnjas, Beenish Khan, and Jennifer Mills, Department of Psychology, York University, Toronto, Ontario, Canada; Anthony G. Greenwald, Department of Psychology, University of Washington; John F. Dovidio, Department of Psychology, Yale University.

The present research was supported by a Social Science and Humanities Council of Canada grant awarded to Kerry Kawakami and National Institute of Mental Health Grants MH-57672 and MH-01533 awarded to Anthony G. Greenwald.

Anthony G. Greenwald is President of Project Implicit, Inc.

Correspondence concerning this article should be addressed to Kerry Kawakami, Department of Psychology, York University, 4700 Keele Street, Toronto, Canada, M3J 1P3. E-mail: kawakami@yorku.ca
In the present research, we investigated how and when social contexts can systematically shape one's working self-concept.

Research from a number of different theoretical perspectives demonstrates that social contexts can impact behaviors, feelings, and attitudes. In general, these studies have provided substantial evidence that people have a strong tendency to synchronize with their social environment and that such processes may be widespread and occur nonconsciously. With respect to behavior, research related to mimicry and the ideomotor effect has shown that participants match the gestures of their interaction partners (Chartrand \& Bargh, 1999) or act in ways that are congruent with behaviors associated with target groups and outgroup exemplars (Bargh, 2006; Bargh, Chen, \& Burrows, 1996; Chen \& Bargh, 1997; Dijksterhuis \& Bargh, 2001; Gabriel, Kawakami, Bartak, Kang, \& Mann, 2010; Hull, Slone, Meteyer, \& Matthews, 2002; Kawakami, Young, \& Dovidio, 2002; S. C. Wheeler $\&$ Petty, 2001). In addition, DeMarree, Wheeler, and Petty (2005; S. C. Wheeler, DeMarree, \& Petty, 2007; S. C. Wheeler \& Petty, 2001) have demonstrated that priming an individual Black exemplar can impact Whites' feelings of aggressiveness, suggesting that participants modified their emotions to better fit outgroup members. Research related to the social tuning hypothesis, alternatively, demonstrates that people also shift their attitudes to match attitudes associated with people in their immediate context (Kawakami, Dovidio, \& Dijksterhuis, 2003; Lowery, Hardin, \& Sinclair, 2001; Sinclair, Lowery, Hardin, \& Colangelo, 2005; Steele \& Ambady, 2006). For example, Sinclair et al. (2005) found that White participants demonstrated less automatic racial prejudice in the presence of a person wearing a t-shirt that conveyed antiracism attitudes (i.e., Eracism).

The primary goal of the present studies was to extend past research on synchronizing with the social environment by examining whether 
activating social categories impacts how people conceptualize the self. Although particular changes to behaviors, emotions, and attitudes will have limited repercussions, changes to the self-concept as a function of activated social categories will have more far-reaching and diverse effects because of the importance of the self as an organizing concept (Leary \& Tangney, 2003). Understanding self-concept dynamics can therefore help integrate and explain findings related to more peripheral, isolated, manifestations of synchronization. Furthermore, although influencing a person's attitudes, behaviors, or emotions may or may not affect one's self-concept, factors that influence one's working self-concept will have broad implications for one's thoughts, feelings, and actions.

Whereas several studies have examined assimilation and contrast effects related to the self-concept as a function of social comparison processes (Dijksterhuis \& van Knippenberg, 1998; Förster, Liberman, \& Kuschel, 2008; Schubert \& Häfner, 2003; Stapel \& Blanton, 2004) and perspective taking (Galinsky, Wang, \& Ku, 2008), the main goal of the present set of studies was to investigate a more general selfsynchronization process. We investigated changes to the self-concept as a direct consequence of exposure to a variety of social categories (i.e., jocks, hippies, the overweight, Blacks, and Asians) when social comparisons are not involved and when people are not explicitly instructed to take the perspective of the target group. In particular, we examined in our experiments the impact of activating specific social categories on associations between the self and stereotypic associations related to the category (Studies 1 and 2), on perceptions of the physical self (Study 3), and associations between the self and target category members.

\section{Factors That Influence Category Activation Can Impact Changes to the Self-Concept}

Because we assume that activating a social category will induce self-synchronization processes, we expect that factors that influence category activation will also impact changes to the selfconcept. Notably, the activation and salience of a specific social category in any given context may be determined by cues related to readily apparent physical characteristics that are deemed to be typical of the group (Fiske, 1998; Kunda \& Spencer, 2003; Stangor \& Lange, 1994; Stangor, Lynch, Duan, \& Glass, 1992). A wide girth, for instance, activates the category overweight, hairstyles activate a sex category, and skin tone activates race (Blair, Judd, \& Fallman, 2004; Livingston \& Brewer, 2002; Macrae, Quinn, Mason, \& Quadflieg, 2005; M. E. Wheeler \& Fiske, 2005). These initial categorizations are assumed to occur without intention, extremely rapidly, and to be driven essentially by perceptual processes (Brewer, 1988; Cloutier, Mason, \& Macrae, 2005; Fiske, Lin, \& Neuberg, 1999; Fiske \& Neuberg, 1990).

It is important to note, however, that when perceiving others, people's attention can be drawn to any one of a number of physical attributes, such as age, race, gender, social class, height, or weight. Although a range of factors can influence which category becomes activated and dominates perceptions (Bargh, Bond, Lombardi, \& Tota, 1986; Bargh et al., 1996; Fiske \& Neuberg, 1990; Gilbert \& Hixon, 1991; Higgins, Rholes, \& Jones, 1977; Srull \& Wyer, 1979; Zárate \& Smith, 1990), social goals in a specific context are assumed to be particularly potent (Fiske \& Neuberg, 1990; Macrae, Bodenhausen, \& Milne, 1995; Stangor et al., 1992) and have been demonstrated to influence categorical processing at the ear- liest stages of person perception (Fiske, 1998; M. E. Wheeler \& Fiske, 2005). A person's current goals with respect to classifying a target have been shown to not only influence which category will be activated but also even whether categorical processing will occur or not. In the present context, we assume that categories with readily apparent physical characteristics and those directly relevant to situational tasks will be activated and subsequently influence the self-concept. Whereas much of the previous research on synchronization has investigated changing attitudes, feelings, and behaviors to match individual partners or a single category exemplar (e.g., Chartrand \& Bargh, 1999; DeMarree et al., 2005; Lowery et al., 2001; Sinclair et al., 2005; van Baaren, Holland, Kawakami, \& van Knippenberg, 2004; van Baaren, Holland, Steenaert, \& van Knippenberg, 2003; cf. Bargh et al., 1996; Hull et al., 2002), we examined in the present studies changing the working self-concept to fit a focal social category in a specific context.

\section{Why Does Self-Synchronization Occur?}

Previous research and theorizing has suggested that one reason why people assimilate overt responses such as their gestures, behaviors, and attitudes to conform to individuals in their immediate environment is to facilitate positive interpersonal relationships (Chartrand, Maddux, \& Lakin, 2005; Dijksterhuis \& Bargh, 2001; Kawakami et al., 2003; Lakin, Jefferis, Cheng, \& Chartrand, 2003). In particular, people will be liked more if they change their overt responses so that they appear to be similar to specific individuals around them. In support of this proposal, mimicking interaction partners can facilitate liking, rapport, and affiliation, which serve to foster personal relationships and prosocial behavior (Chartrand \& Bargh, 1999; Lakin et al., 2003; van Baaren et al., 2004, 2003). Notably, because of its important adaptive function and usefulness at an evolutionary level (Lakin $\&$ Chartrand, 2003), people may change these more overt responses even when they are not in the direct presence of the target (DeMarree et al., 2005; Hsee, Hatfield, Carlson, \& Chemtob, 1990; Kawakami et al., 2002; Neumann \& Strack, 2000).

Furthermore, research has demonstrated that these types of overt interpersonal responses can be influenced by affiliative motives (Lakin et al., 2003) and particular characteristics of the target person (e.g., friendliness, likability, and extremity) and of the perceiver (e.g., individual differences in self-monitoring and selfconsciousness). For example, Sinclair et al. (2005) found that participants tuned their social attitudes to fit the attitudes of a likable but not rude experimenter. Likewise, self-monitoring, which is a strategy that people use to create positive impressions in a specific context, can impact synchronization effects (Cheng \& Chartrand, 2003; DeMarree et al., 2005). Hull et al. (2002) further identified self-consciousness, which influences the extent to which a prime is perceived to be self-relevant, as an important moderator. Whereas these latter researchers have implicated the self in synchronization processes, their focus has been on changes to emotions and behaviors and how this type of process might be influenced by the self. In the present research, alternatively, we investigated the self as a dependent rather than an independent variable by concentrating on how the working self-concept adapts to fit a particular activated social category.

Although matching overt responses, such as expressed attitudes and behaviors, with those of an interaction partner appears to have obvious benefits because it facilitates interpersonal interactions, 
the reason why people might change their more internal associations with the self to match those of another social category is less intuitive. In fact, modifying the working self-concept so that it is congruent with activated social categories would not necessarily increase popularity because these changes are not directly observable to others. We propose that one reason why people might change their self-concept to match salient social categories is because they want to perceive themselves as fitting into their social environment. Given that belonging to social groups is critical to human survival and who we are (Baumeister \& Leary, 1995; Gabriel \& Young, 2011; Gabriel et al., 2010; Gardner, Pickett, \& Brewer, 2000; Maslow, 1968; Schaller, Conway, \& Peavy, 2010), people may self-synchronize to an activated social category as a way of filling a need to interconnect with their social context.

Cross-cultural researchers, however, suggest that people may differ in their need to construe themselves as interconnected with their social environment. They propose that whereas people with an independent self-construal attempt to define the self as largely separate and distinct from other people, people with an interdependent self-construal attempt to define the self in terms of relationships and connections with people and groups (Kitayama \& Markus, 1995). Specifically, people with an interdependent, in comparison to an independent, self place more importance on belonging and fitting into their social context and less emphasis on personal goals. Although these two types of orientations were originally conceptualized as culturally determined selfschemas, associated with more individualistic Western and collectivistic Eastern cultures, respectively, recent studies have demonstrated that experimental priming manipulations can influence the activation of an independent or interdependent self-construal. Importantly, the consequences of these manipulations have been shown to mirror cross-cultural effects on an individual's cognitive and motivational processes (Aaker \& Lee, 2001; Gardner, Gabriel, \& Lee, 1999; Gardner et al., 2000; Hong, Morris, Chiu, \& Benet-Martinez, 2000; Lee, Lee, \& Kern, 2011; Trafimow, Triandis, \& Goto, 1991). Thus, a further goal of the present research was to investigate whether a need to interconnect, related to a more interdependent versus independent self-construal, influences the impact of activated social categories on changes to the working self-concept.

\section{Overview of the Present Studies}

The primary goal of the present research was to examine whether the activation of social categories influences key components of the self-concept. The second aim was to investigate whether factors that influence the activation of social categories such as contextual goals and factors that impact motivations to interconnect moderate these self-synchronization processes. In general, we hypothesized that the impact of activated social categories goes beyond peripheral, isolated manifestations of synchronization related to emotions, attitudes, and behaviors to influence the working self-concept more holistically. In particular, in Study 1 we predicted that priming participants with either hippies or jocks will increase the speed with which they associated the self with characteristics related to these activated categories. In Studies 2 and 3, we explored the effect of contextual social goals on this process. We predicted that goal instructions related to the category overweight will increase the speed with which participants associated the self with terms related to being overweight and impact participants' perceptions of their own physical body. Finally, in Study 4 we used a classic manipulation of self-construal to investigate one possible explanation for self-synchronization effects-the need to feel interconnected. We predicted that people will be more likely to change their working self-concept to match activated racial groups when interdependent rather independent self-construals were primed.

\section{Study 1}

The aim of Study 1 was to initially investigate the impact of activated social categories on associations between the self and stereotypic traits related to the target group. In particular, participants were first primed with a specific category, either hippies or jocks, before completing an Implicit Association Test (IAT) related to selfassociations (Greenwald \& Farnham, 2000; Greenwald et al., 2002; Kawakami, Steele, Cifa, Phills, \& Dovidio, 2008; Nosek, Banaji, \& Greenwald, 2002). We predicted that participants primed with hippies compared with jocks would be faster to associate the self with concepts related to hippies relative to jocks on the IAT.

\section{Method}

Participants and design. Although 51 undergraduate students took part in the experiment for course credit, the data from four students who did not follow instructions or complete the study were excluded from the analyses. The remaining 38 female and 9 male participants were randomly assigned to a social category prime condition (hippie vs. jock) in a between-subjects design.

\section{Procedure.}

Social category priming task. Upon arrival, participants were led to individual cubicles and seated in front of a personal computer. To activate a specific social category, participants were presented with a series of images of individuals who were all readily identifiable as either hippies or jocks by virtue of physical characteristics and clothing. These photographs were interspersed with images of furniture. ${ }^{1}$ Specifically, participants in the hippie prime condition were shown 10 images of individuals with visual cues associated with hippies (e.g., long hair, flowing clothes) and 10 images of furniture. Participants in the jock prime condition, alternatively, were shown 10 images of individuals with visual cues associated with athletes (e.g., short hair, strong bodies, athletic gear) and 10 images of furniture. The main assumption behind this task was that the presentation of individuals with featural cues strongly associated with a specific category will activate that category (Fiske, 1998; M. E. Wheeler \& Fiske, 2005).

The 20 images in both conditions were presented twice in a random order, and participants were asked to categorize as quickly and accurately as possible whether the person or object in the image had hair. If the image had hair, participants were instructed

\footnotetext{
${ }^{1}$ In an initial pilot test, 20 participants were asked to rate the degree to which the images in the social category priming task and the traits in the IAT were associated in our culture with the social categories of hippies and jocks on a 9-point scale ranging from 1 (not at all associated) to 9 (extremely associated). As expected, the 10 images and six stereotypic words related to hippies were associated significantly more with the hippie $(M \mathrm{~s}=6.61$ and 7.03$)$ than the jock $(M \mathrm{~s}=2.30$ and 3.57) category, $t s(19)=10.71$ and 11.53, respectively, $p s<.001$. Alternatively, the 10 images and six stereotypic words related to jocks were associated significantly more with the jock $(M \mathrm{~s}=8.37$ and 7.11$)$ than the hippie $(M \mathrm{~s}=$ 1.51 and 3.23) category, $t s(19)=20.33$ and 11.20 , respectively, $p s<.001$.
} 
to press $E$ on the keyboard, and if the image did not have hair, participants were instructed to press $I$. On each trial, participants were presented with an image of a person or a piece of furniture until they responded. If participants made a correct response (i.e., for images of people, regardless of whether they were hippies or jocks, this was "hair," and for images of furniture this was "no hair"), a blank screen was presented for $400 \mathrm{~ms}$ before the next trial. If participants made an incorrect response (i.e., for images of people this was "no hair" and for images of furniture this was "hair"), a blank screen was presented for $400 \mathrm{~ms}$, followed by a red $X$ for $450 \mathrm{~ms}$, and another blank screen for $400 \mathrm{~ms}$ before the next trial. All participants were presented with a total of 40 trials.

The IAT. After completing the social category priming task, all participants were introduced to the IAT. This reaction time task administered on a computer limits the effects of strategic selfpresentation while measuring the participant's implicit selfconcept (Greenwald \& Farnham, 2000; Greenwald et al., 2002). In particular, the task was designed to assess the strength of association between the self and traits related to hippies and jocks by presenting participants with six concepts related to hippies (i.e., alternative, organic, activist, environmentalist, carefree, and hippie) and jocks (i.e., athlete, sporty, muscular, competitor, disciplined, and jock) and four self-related (i.e., I, me, mine, andself) and other-related (i.e., they, them, their, andother) words.

In accordance with standard IAT procedures, following several practice blocks, participants were presented with two critical blocks consisting of 60 trials each. The order of blocks was counterbalanced across participants. In one critical block, participants were instructed to use one key when categorizing jocks and self words and another key when categorizing hippies and others words. In the other critical block, these pairings were reversed and participants were instructed to use one key when categorizing jocks and others words and another key for hippies and self words. On each specific trial, participants were required to categorize the word or photograph according to one of the four categories (i.e., hippie, jock, self, other) using the appropriate key. If the participant made a correct response, a blank screen was presented for 400 $\mathrm{ms}$ before the next trial. If the participant made an incorrect response, a blank screen was presented for $400 \mathrm{~ms}$, followed by a red $X$ for $450 \mathrm{~ms}$, and another blank screen for $400 \mathrm{~ms}$ before the next trial.

For purposes of comparison and because of the ease of millisecond latency interpretations, analyses were carried out on IAT scores that were calculated using the traditional scoring algorithms related to mean millisecond differences and the new scoring algorithms related to $D$ scores (Greenwald, McGhee, \& Schwartz, 1998; Greenwald, Nosek, \& Banaji, 2003). In particular, both types of IAT scores were created by calculating the difference between the two critical blocks, with higher scores representing stronger associations between the self and characteristics associated with jocks in comparison to hippies.

The main premise underlying the IAT is that a person will be faster at pairing concepts that are conceptually associated than concepts that are unrelated (Greenwald et al., 1998; Nosek et al., 2002). In the present context, for example, if a person associated the self more with traits related with jocks than hippies, they would be faster during the block when the self shared the same key as jocks than during the block when the self shared the same key as hippies. Although we assumed in the present study that the extent to which people have associations with a specific trait will be influenced by their initial self-concept, we expected changes in the working self-concept such that the self will be associated relatively more with traits related to the target category after that category has been activated compared with an alternative category prime. Because this procedure focuses on relative differences in response latencies when the same stimuli are presented with the self and others, idiosyncrasies related to the stimuli are less critical. Moreover, our main hypotheses concerned differences in the IAT scores across different category priming conditions, and therefore our focus was on changes in self-associations with specific traits and social categories.

On the basis of previous findings related to social tuning effects by Kawakami et al. (2003), the activation of a specific category was not expected to impact associations of stereotypic characteristics with generic others. If people synchronize the self to match activated social categories so that they feel more interconnected with their social environment, it was expected that social category activation would mainly increase overlap between the self and the primed category rather than between some generic unspecified others and the target category. In accordance with standard IAT theorizing (Greenwald \& Farnham, 2000; Pinter \& Greenwald, 2005), the term other in this test is used as a comparison category to the self and therefore represents something that is not the self and relatively neutral. In particular, the IAT does not compare associations between the self and generic nonspecified others, but in accordance with the main aim of this investigation, it tests associations between the self (as opposed to generic others) and a specific activated category. There is a long tradition in selfresearch of using the nonspecific other category as a suitable comparison (Pinter \& Greenwald, 2005). In the present context, because self-synchronization fills participants' needs to feel interconnected with a specific social group, it was proposed that people match the self to a target category activated in their immediate context and that perceptions of more generic nonspecific others remain unchanged.

At the end of the experimental session, all participants were asked to describe their perceptions of the main goal of each "study," their beliefs concerning the expectations of the experimenter, and their perceptions of the relationship between the studies. As expected, none of the participants in Study 1, or any of the subsequent experiments, reported any suspicion regarding the relationship between the priming task and the main dependent variables (i.e., the IATs or the self-perception task) or provided any hypotheses that were related to the actual predictions (Bargh et al., 1996; Chartrand \& Bargh, 1996).

\section{Results and Discussion}

To examine the effect of social category priming on the speed with which participants associated characteristics related to hippies and jocks with themselves, we performed a $t$ test on the IAT responses related to mean millisecond differences and the $D$ scores. Higher scores indicate stronger associations between the self and characteristics related to jocks in comparison to hippies. As expected, participants in the jock prime condition were faster at associating the self with characteristics related to jocks ( $M$ and $D=42$ and .12) than participants in the hippie prime condition $(M$ 
and $D=-18$ and -.06$), t \mathrm{~s}(45)=2.37$ and 2.40 , respectively, $p \mathrm{~s}<.03 .^{2}$

It is important to note that differences we obtained on the IAT between the jock and social category priming conditions do not indicate a general increase in the accessibility of stereotypes following a social category prime. If that were the case, the IAT effects, because they involve a direct comparison of responses in decisions about the "self" and "others," would be zero. There would be no difference between the speed with which participants associated hippie or jock traits with the self versus others. The differences that we found on the IAT reveal that participants were faster at responding when stereotypic traits related to the primed category were associated with the self versus others, implying specific changes in the working self-concept (Markus \& Kunda, 1986).

Overall, then, the results from Study 1 provide initial evidence that social category priming can directly influence implicit selfconcepts. To activate a specific social category in this study, participants were presented with photographs of individuals who were easily recognizable as either athletes or hippies. Although their task was to classify the stimuli according to whether the stimuli (i.e., furniture and people) had hair or no hair, we expected that because all the photographs of people in each separate condition had physical characteristics that were readily apparent and strongly associated with a specific social category, participants would activate this category and would subsequently synchronize the self with this group. Our findings support this assumptionparticipants who were initially presented with jocks in comparison to hippies were significantly faster to associate the self with characteristics related to an athlete (e.g., disciplined, competitive) relative to characteristics related to an alternative lifestyle (e.g., carefree, organic).

\section{Study 2}

The primary goal of Study 2 was to replicate the results from Study 1 with a different social category. Rather than assimilating to characteristics associated with hippies or jocks, we investigated in this study self-synchronization related to the category overweight.

A further aim of Study 2 was to investigate the importance of contextual social goals on this process. Although research has convincingly demonstrated that category activations are often driven by physical cues and readily available visual features of social stimuli, contextual goals have been shown to influence which categories become activated and the extent of category activation (Fiske, 1998; Macrae et al., 1995; Stangor et al., 1992; M. E. Wheeler \& Fiske, 2005). For example, Kawakami et al. (2002) have shown that participants instructed to categorize photographs of the young and elderly as "old" or "not old" automatically activated traits related to the elderly and demonstrated ideomotor effects related to behaviors associated with the elderly. Although photographs of both the young and the elderly were presented, task orientation in this specific context and the explicit goal to classify stimuli according to membership in the elderly target category determined which category was activated and influenced stereotype and behavioral activations. Importantly, these findings suggest that in social contexts in which multiple categories are present, contextual goals can influence which category dominates activation and, therefore, can influence selfsynchronization effects.

To initially test our assumption that contextual goals influence category activation, we ran a pilot study in which half the participants were presented with a series of images of overweight and standard models and were instructed to categorize the models according to whether they needed to lose weight or not, and the remaining half of participants were not presented with an initial task. All participants were subsequently instructed to solve a word completion task to examine category activation (Bassili \& Smith, 1986; Dovidio, Kawakami, Johnson, Johnson, \& Howard, 1997; Gilbert \& Hixon, 1991). Specifically, they were presented in a random order with three word stems (i.e., $\mathrm{f}_{-}$, hea ${ }_{-}$, and $\mathrm{b}_{-}$ g) that potentially could be related to the overweight category (i.e., fat, heavy, and big) and three word stems (i.e., th _ n, sl _ m, sma _ _) that potentially could be related to the thin category (i.e., thin, slim, and small).

As expected, a significant two-way interaction was found, $F(1$, $28)=4.78, p<.05$. Participants presented with both overweight and standard models and instructed to focus on whether the person needed to lose weight completed more of the words with concepts related to the category overweight $(M=46 \%)$ than participants in the no-prime condition $(M=29 \%), t(28)=2.21, p<.05$. Furthermore, participants in the overweight task $(M=50 \%)$ and no-task $(M=57 \%)$ conditions did not differ in the number of word completions related to thin words, $t(28)=.68, p=.50$. In accordance with earlier findings (Kawakami et al., 2002; Macrae et al., 1995; Stangor et al., 1992), these results support the assumption that contextual social goals can determine the activation of specific categories.

In Study 2, we assumed that if contextual goals influence the activation of social categories, as demonstrated in the pilot study, they would also influence subsequent self-synchronization processes. Specifically, participants were presented with the same social goals task used in the pilot study. Rather than a word completion task to measure category activation, however, the participants were presented with an IAT similar to the one used in Study 1 but related to overweight and not overweight categories.

It is important to note that although the results from Study 1 demonstrated that social category priming influenced the extent to which participants associated particular characteristics with the self, it is unclear whether these effects were related to weaker associations with traits that were incongruent with the activated category prime (i.e., alternative stereotypes after the jock prime and athletic stereotypes after the hippie prime) rather than stronger associations with traits that were congruent with the activated

\footnotetext{
${ }^{2}$ Although sex of participant was included as a factor in the initial analysis in all studies, this factor did not qualify the predicted effects. Please note that the degrees of freedom may vary slightly from the main analyses related to the IAT scores because some participants failed to report their sex. Specifically, the interaction between sex of participant and social category prime in Study 1 was not significant, $F_{\mathrm{s}}(1,43)=0.46$ and $0.41, p s>.50$. The interaction between sex of participant and social goal task in Study 2 was also not significant, $F_{\mathrm{s}}(2,73)=0.37$ and $1.40, p \mathrm{~s}>$ 25. In Study 3 , the interaction between sex of participant and social goal task was not significant, $F(2,38)=0.53, p=.59$. Finally, in Study 4 , the interaction between sex of participant, self-construal task, and social category was also not significant, $F \mathrm{~s}(1,74)=0.54$ and $0.95, p \mathrm{~s}>.32$.
} 
category prime (i.e., alternative stereotypes after the hippie prime and athletic stereotypes after the jock prime). Although previous studies related to social tuning and ideomotor effects (Kawakami et al., 2003, 2002) suggest that this alternative explanation is unlikely, a control condition was included in Study 2 in which participants did not receive an initial priming task. An additional condition was also included in which participants were required to classify geometric shapes according to size. Although participants in this condition focused on the size of the stimuli like participants in the overweight task condition, we did not expect this task to impact their self-concept because we assumed that people only attempt to match the self to activated categories that are animate and social, not inanimate in nature.

In summary, we predicted that when participants were presented with the social goal to classify both overweight and standard models according to whether they were overweight, they would activate the category overweight and subsequently change their self-concept to match this group. These participants would therefore associate themselves faster with overweight concepts than participants in the no-priming task condition. We further predicted no difference in the speed with which participants associated overweight traits with the self between participants in the geometric shape task and the no-prime conditions.

\section{Method}

Participants and design. Although 90 undergraduate students took part in the experiment for course credit, the data from nine students who did not follow instructions or complete the study and two students with a large percentage of extreme outliers in their response latencies (more than 20\%) were excluded from analyses. The remaining 55 female and 24 male participants, who the experimenter perceived to be thin to average weight, were randomly assigned to social goal task condition (overweight task vs. geometric shapes task vs. no task) in a between-subjects design.

\section{Procedure.}

Social goal task. Upon entering the laboratory, participants were led to individual cubicles and seated in front of a personal computer. To activate the category overweight, participants were presented with the social goal task. Specifically, participants in the overweight task condition were presented twice with 10 images of standard models as well as 10 images of plus size models in a random order. Participants in this condition were instructed to categorize each woman according to societal, not personal, standards of whether she "needs to lose weight" or does "not need to lose weight" by pressing either $E$ or $I$ on the keyboard. We expected these instructions to focus participants on the extent to which the person was deemed to be too heavy and activate the social category overweight (Kawakami et al., 2002). Participants in the geometric shapes task condition, alternatively, were presented twice with 10 images of geometric shapes that were wide and 10 images of geometric shapes that were not wide in a random order. Participants in this condition were informed that their task was to categorize each shape according to whether the image was "wide" or "not wide" by pressing the appropriate key. On each trial, participants were presented with a model or geometric shape until they responded, followed by a blank screen for $400 \mathrm{~ms}$ before the next trial. Although participants in both task conditions were instructed to complete the 40 classification trials as quickly and accurately as possible, participants in the no-task condition were presented immediately with the IAT.

The IAT. To examine the effect of the social goal task on associations between the self and overweight concepts, all participants were presented with an IAT that was conceptually similar to the procedure used in Study 1. Although the target stimuli related to self and others in this task remained the same, four words related to being overweight (e.g., plump, chubby, hefty, chunky) and not overweight (e.g., slim, skinny, slender, thin) replaced the words related to hippies and jocks. One set of critical trials required participants to press one key when categorizing self and overweight words and another key when categorizing others and not overweight words. The alternative set of critical trials required participants to press one key when categorizing self and not overweight words and another key when categorizing others and overweight words. The presentation latencies and error messages in this task were the same as in Study 1. Each critical block in this task consisted of 80 trials, and the order of the two critical blocks was counterbalanced. IAT scores were created by calculating the difference in response latencies between the two critical blocks. Higher scores reflected stronger associations between the self and characteristics associated with overweight people in comparison to thin people.

\section{Results and Discussion}

To examine the effect of social category activation on the speed with which participants associated traits related to the category overweight with the self, we performed a one-way analysis of variance social goals task (overweight task vs. geometric shapes task vs. no task) on the IAT responses related to mean millisecond differences and the $D$ scores. A significant effect for social goal task was found on the traditional IAT scores, $F(2,76)=3.83, p<$ .04 , and a marginally significant effect was found on the $D$ scores, $F(2,76)=2.51, p<.09$. Simple effects analyses demonstrated that participants in the overweight task condition were faster at associating the self with overweight concepts $(M$ and $D=-113$ and -.20$)$ than participants in the no-task control condition $(M$ and $D=-202$ and -.34$), t \mathrm{~s}(49)=2.52$ and 2.28 , respectively, $p \mathrm{~s}<$ .04 . Furthermore, as expected, participants in the geometric shapes task condition ( $M$ and $D=-172$ and -.28 ) were as slow at associating overweight terms with the self as participants in the no-task condition $(M$ and $D=-202$ and -.34$), t \mathrm{~s}(49)=0.88$ and 0.73 , respectively, $p s>.37$.

The results from Study 2 conceptually replicated the findings in Study 1 by showing that priming specific target categories can influence the extent to which participants associate characteristics related to that category with the self. Furthermore, whereas the focus of Study 1 was on hippies and jocks and traits associated with those categories such as alternative and athletic, the focus of Study 2 was on the impact of activating the category "overweight." The findings demonstrate that when participants were presented with overweight and standard weight category members and instructed to categorize these people according to needing to lose weight, they activated the category overweight and, therefore, were faster to associate concepts related to this category such as chubby and hefty with the self than participants in control conditions. Notably, participants in the overweight prime condition did not associate overweight concepts with the self more than thin 
concepts in absolute terms. But these thin to average weight participants did associate overweight concepts relatively more with the self when the overweight category was activated compared with control conditions. Although we acknowledge that people's initial, more stable, self-concept can constrain the extent to which they associate particular characteristics with the self, the present findings suggest that social category activations can influence in predicted ways the working self-concept.

Furthermore, the results suggest that contextual social goals can determine specific social category activation as demonstrated by the pilot study and past research (Kawakami et al., 2002) and, therefore, influence subsequent self-synchronization processes. Tasks which focus on whether exemplars belong to the category overweight increased participants' tendency to associate characteristics related to the overweight with the self.

\section{Study 3}

The primary goal of Study 3 was to examine the effect of social category activations on another aspect of the self-concept-selfperceptions. Although we investigated in the first two studies assimilating the self to characteristics and stereotypes related to the primed category, in this study we extended this initial work by exploring whether participants synchronize perceptions of their personal physical characteristics to match activated social categories.

To examine this possibility, participants attended two different sessions. In the first session, a photograph of each participant was taken with a digital camera and subsequently manipulated to create a series of images that portrayed the person as being more or less heavy than their actual self. In the second session, participants were required either to complete the social goals task used in Study 2 in which they categorized models in terms of whether they needed to lose weight or geometric shapes in terms of whether they were wide or they did not complete this initial task. Next, all participants were presented with a series of self-images and instructed to select the image they believed was the actual depiction of the self. We predicted that participants in the overweight task condition would select a heavier image of themselves than participants in the no-task condition. Participants in the geometric shapes task condition who did not focus on animate social categories, however, were not expected to modify their self-concept and, therefore, would choose self-images that did not differ from the no-task condition.

\section{Method}

Participants and design. Although 43 undergraduate students took part in the experiment for course credit, the data from two students who did not complete the study were excluded from the analyses. The remaining 29 female and 12 male participants, who the experimenter perceived to be thin to average weight, were randomly assigned to social goal task condition (overweight task vs. geometric shapes task vs. no task) in a between-subjects design.

Procedure. In the first session, all participants completed an unrelated study before having their photograph taken with a digital camera. The photograph was a frontal head and body shot of the student against a white background. In the week between the first and second sessions, these photographs were manipulated using a graphic image altering program (Mills, 2000). This program was specifically designed to modify images of people according to weight. These adapted images were subsequently used in the self-perception task in the second session. In particular, when participants returned to the laboratory, they were presented with two ostensibly separate "studies." The actual goal of these related tasks was to activate the category overweight in the social goal task and to examine the effect of this task on the participants' perceptions of their own body weight.

Social goal task. Participants upon entering the laboratory for the second session were led to individual cubicles and seated in front of a computer. After initial instructions, participants were either presented with the overweight task to activate the category overweight or the geometric shapes tasks or they did not complete this priming task.

Self-perception task. Next, in order to examine the impact of the social goal task on perceptions of the physical self, all participants were presented with a self-perception task in which a series of separate images of the person were presented. These images differed in the extent to which the participants' body size was larger or smaller. While Image 7 depicted the actual photograph that was taken of the participant, each image between 6 and 1 depicted an image of the participant that was incrementally thinner in body width. Alternatively, each image between 8 and 13 depicted an image of the participant that was incrementally larger in body width. On each trial, the participant was presented with a sequence of separate images of the self which ranged from 1 , the thinnest image, to 13 , the most overweight image. The participant was instructed to choose the image that depicted their actual body.

This task was composed of three trials. In the first trial, participants were presented with their most overweight body image (i.e., Image 13) and instructed to go through the images on the computer screen until they reached the appropriate image. Participants were able to view both thinner and more overweight images of the self by simply clicking on arrows. Once participants had selected the image that they thought was their actual body size, they were presented with the second and third trials, which started with the thinnest body image (i.e., Image 1) and the actual photograph of their body (i.e., Image 7), respectively. Participants were instructed on each of these trials to choose an image that was the most accurate depiction of their body.

\section{Results and Discussion}

To examine the effect of activating the category overweight on perceptions of the physical self, we performed a Social Goal Task (overweight task vs. geometric shapes task vs. no task) $\times$ Type of Initial Body Presentation (overweight self vs. thin self vs. actual self) analysis of variance on the participants' selection of a self-image with repeated measures on the type of initial body presentation. We found a main effect for type of initial body presentation, $F(2,38)=7.92$, $p<.001$. Not surprisingly, simple effects analyses showed that when the first image on the self-perception task was the most overweight depiction, participants chose a more overweight self $(M=8.22)$ than when the task started with an image of the person that was not modified $(M=7.02), t(40)=2.98, p<.01$. Alternatively, when the first image on the self-perception task was the least overweight depiction, participants chose a less overweight self $(M=6.32)$ than 
when the task started with the image that was not modified $(M=$ 7.02), $t(40)=2.06, p<.05$.

More importantly, the social goal task was also found to significantly influence self-perceptions, $F(2,38)=6.21, p<.01$. As expected and depicted in Figure 1, this effect was not qualified by the type of initial body presentation. Specifically, the Social Goal Task $\times$ Type of Initial Body Presentation interaction was not significant, $F(4,36)=0.36, p=.84$. Furthermore, simple effects analyses related to the main effect for social goal task demonstrated that participants in the overweight task condition chose a more overweight image of the self $(M=8.54)$ than participants in the no-task condition $(M=7.07), t(25)=2.20, p<.05$. Also, as expected, participants in the geometric shapes task condition $(M=$ 6.29) did not differ in their choice of self-image from participants in the no-task condition $(M=7.07), t(26)=1.34, p=.19$.

Additional analyses separately compared the difference in each task condition between the actual photograph of the unaltered image of the self (Image 7) and the participants' selection of the body image that they thought was the correct depiction. These analyses showed that although the images selected by participants in the geometric shape task condition, $t(13)=1.60, p=.13$, and the no-task condition, $t(13)=0.18, p=.85$, did not significantly differ from the unmodified actual body image, the image selected by participants in the overweight task condition did differ, $t(12)=2.75, p<.05$. Although seven images were presented to the participants in which their body width grew incrementally and seven images were presented in which their body width decreased incrementally, these changes were not related to symmetrical changes in the photograph width. Each point, however, was associated with small but perceptible increases or decreases in the size of participants' body portrayed in the image. Notably, the results related to the control condition provide evidence that participants were remarkably accurate in their self-perceptions choosing a shape that was close to the actual depiction of their body. Only when participants were initially primed with the category overweight did they vary in these self-perceptions by selecting a selfdepiction that was significantly more overweight than their actual image.

To examine whether the effect of priming overweight people was specific to self-perceptions or influenced perceptions of others as well, an additional separate group of participants was presented with the

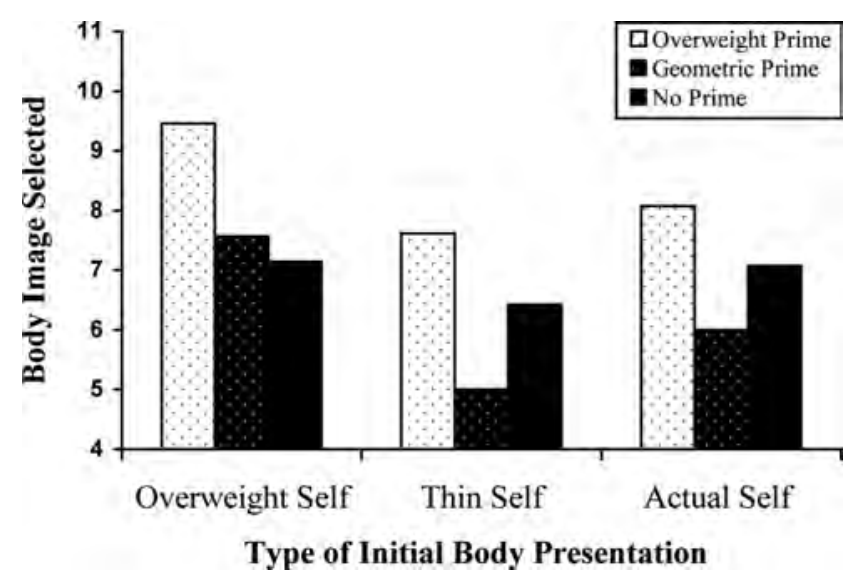

Figure 1. Effects of social category prime and type of initial body presentation on perceptions of the physical self in Study 3. overweight priming condition and subsequently asked to select the correct image not of themselves but of a female experimenter. This experimenter had provided them with initial research instructions and had subsequently waited outside the cubicle. A comparison of the difference after overweight priming between the actual photograph of the unaltered experimenter and participants' selection of the body image that they thought was the correct depiction of the experimenter was not significant, $t(16)=1.02, p=.32$. Indeed, participants' selection of the correct depiction from the 13 images of the experimenter $(M=6.55)$ was remarkably close to the unaltered photograph of the experimenter (Image 7). Furthermore, a comparison of the difference after overweight priming between participants' selection of the most accurate depiction of their own body image $(M=8.54)$ and the body image of the experimenter $(M=6.55)$ was significantly different, $t(28)=2.83, p<.01$. As expected, based on previous results related to social tuning (Kawakami et al., 2003) and the significant IAT effects in Studies 1 and 2, participants only assimilated perceptions of their own body, and not the experimenter's body, to the overweight category prime.

In accordance with Study 2, these results demonstrated that when presented with a goal to focus on the extent to which stimuli targets were overweight, participants activated this category and selected a more overweight image as an accurate depiction of themselves than participants in a control condition. Notably, even though the target group, overweight, is negatively evaluated in Western society (Crandall, Nierman, \& Hebl, 2009), participants adapted two important aspects of their self-concept (traits and self-perceptions) to match this category. On the basis of present societal norms to be thin, one would assume that on an explicit level these participants would be more motivated to contrast rather than assimilate the self to this group.

\section{Study 4}

The purpose of Study 4 was threefold. First, we explored a potential boundary condition for self-synchronization. Although all categories to a certain extent may be related to possible selves (Markus \& Kunda, 1986; Markus \& Nurius, 1986; S. C. Wheeler, DeMarree, \& Petty, 2005), it seems likely that it is easier to associate the self with some categories than with others. We used primes of categories with permeable boundaries in our first three studies: hippies, jocks, and the overweight. Racial categories, in contrast, are groups that have a strong, traditional essentialist quality (Haslam, Rothschild, \& Ernst, 2000; Leyens, Desert, Croizet, \& Darcis, 2000; Rothbart \& Taylor, 1992; Yzerbyt, Corneille, \& Estrada, 2001). The boundary for membership in another racial group is generally perceived to be impermeable. Thus, for people who are not Black, it may be much more difficult to conceive of a possible self that is Black than overweight, athletic, or alternative. To examine the generalizability and potential limits of selfsynchronization effects, in Study 4 we investigated whether activating a racial category would also result in assimilation to the target group.

Second, we investigated in Study 4 the impact of activated social categories on another aspect of the self-conceptidentification with members of the target category. Specifically, we tested whether participants would be faster to associate Blacks 
relative to Asians with the self after the Black category was activated.

Third, a key goal of Study 4 was to investigate one possible explanation for why self-synchronization occurs. Specifically, we examined whether manipulating the need to interconnect with social categories, by priming either interdependence versus independence, influenced these harmonization processes. On the basis of the premise that self-synchronization processes are related to a need to construe the self as interconnected with one's social environment, we predicted that focusing participants on a self that is embedded in a social context versus a self that is separate and distinct (Gardner et al., 1999; Lee et al., 2011; Trafimow et al., 1991) would increase the extent to which people change their self-concept to match the activated social category.

In particular, participants in Study 4 were instructed to complete an initial self-construal task in which either an interdependent or independent self was primed. Next, participants who identified themselves as neither Black nor Asian were either presented with images of Blacks or Asians during a modified version of the person/furniture classification task used in Study 1. Finally, all participants completed a category IAT in which they were asked to respond to photographs of Blacks and Asians and words related to the self and others.

We predicted that an interdependent versus independent selfconstrual would interact with the activated social category to influence self-synchronization. In particular, we expected that participants whose interdependent self-construal was made temporarily accessible would be faster to associate the self with Blacks when primed with Blacks in comparison to Asians. Alternatively, we expected that participants whose independent self-construal was made temporarily accessible would not differ in the speed with which they associated themselves with Blacks after activating Black or Asian categories.

\section{Method}

Participants and design. Although 89 undergraduate students took part in the experiment for course credit or a movie ticket, the data from seven students who did not understand or follow instructions were excluded from the analyses. The remaining 57 female and 25 male non-Asian and non-Black participants were randomly assigned to condition in a 2 (self-construal task: interdependent vs. independent) $\times 2$ (social category priming condition: Blacks vs. Asians) between-subjects design.

\section{Procedure.}

Self-construal task. Upon arrival in the lab, participants were seated in individual cubicles in front of a personal computer and informed that they would be completing a series of unrelated tasks. Participants were told that the first task would involve reading a short story. The goal of this task was to prime an independent versus interdependent self (Gardner et al., 1999; Lee et al., 2011; Trafimow et al., 1991). Each story began by describing a fictional warrior named Sostoras who must choose a commander to lead an important military mission. Participants in the independent prime condition read a version of the story in which Sostoras decides to dispatch a talented general based on the general's individual merits and whose success would in turn earn Sostoras many benefits. The focus of this story was on Sostoras' decision to enhance his own individual standing and to promote his personal power and pres- tige. Participants in the interdependent prime condition, alternatively, read a version of the story in which Sostoras decides to dispatch a relative, whose success would ultimately benefit Sostoras' entire family. The focus of this story was on Sostoras' decision to show loyalty and to promote his family group's power and prestige. After reading the scenario, participants were required to rate the extent to which Sostoras' decision was strategic using a 7-point scale ranging from 1 (not at all strategic) to 7 (very strategic).

Social categorization priming task. Participants also completed an apparently separate task designed to activate a specific social category. In particular, participants were instructed to complete a classification task related to people and furniture that was similar to the procedure used in Study 1. Specifically, participants in the Black prime condition were shown 10 images of Blacks and 10 images of furniture. Participants in the Asian prime condition, alternatively, were presented with 10 images of Asians and 10 images of furniture.

In both conditions, the stimuli were presented twice in a random order, and participants were required to categorize as quickly and accurately as possible whether the person or object in the image was animate or inanimate by pressing $E$ or $I$ on the keyboard. The presentation latencies and error messages in this task were the same as in Study 1, and participants in both priming conditions completed 40 trials. In accordance with Study 1, we assumed that because all the photographs of people in each condition had physical characteristics that were readily apparent and strongly associated with a specific racial category, participants would activate the targeted Black or Asian categories accordingly.

The IAT. To examine the effects of social category primes on self-associations, all participants were presented with an IAT. In contrast to the IATs in Studies 1 and 2, which were related to traits associated with the primed category, the present study compared the speed with which participants identified with actual members of two categories-Blacks and Asians. Although the target stimuli related to the self and others remained the same as in previous experiments, photographs of six Blacks (three female and three male) and six Asians (three female and three male) replaced previous characteristics.

One set of critical trials in this task required participants to press one key for self words and photographs of Blacks and another key for words related to others and photographs of Asians. Another set of critical trials required participants to press one key for self words and photographs of Asians and another key for words related to others and photographs of Blacks. It is important to note that none of the photographs used in the category priming task were used in the IAT. The presentation latencies and error messages were the same as those in the previous IATs. Each critical block consisted of 60 trials, and the order of the critical blocks was counterbalanced. IAT scores were created by calculating the difference between the two critical blocks, with higher scores reflecting stronger associations between the self and Blacks in comparison to Asians.

\section{Results and Discussion}

To examine the effect of activated social categories and selfconstruals on the speed with which participants associated Blacks with the self, we performed a Self-Construal Task (interdependent 
vs. independent) $\times$ Social Category Prime (Blacks vs. Asians) analysis of variance on the IAT responses related to mean millisecond differences and the $D$ scores. As predicted, only the twoway interaction was significant, $F \mathrm{~s}(1,78)=8.06$ and 9.22 , respectively, $p s<.01$. Simple effects analysis revealed that when initially exposed to interdependent self-construals, participants assimilated to the activated social categories and associated themselves more with Blacks when primed with Blacks ( $M$ and $D=86$ and .23) than when primed with Asians ( $M$ and $D=-32$ and $-.04), t \mathrm{~s}(41)=2.43$ and 2.48 , respectively, $p \mathrm{~s}<.05$. When initially exposed to independent self-construals, alternatively, participants were nonsignificantly less likely to associate the self with Blacks when the category Blacks ( $M$ and $D=13$ and .01) in comparison to Asians ( $M$ and $D=79$ and .23) was activated, $t \mathrm{~s}(37)=1.53$ and $1.88, p \mathrm{~s}<.14$.

We extended theorizing in Study 4 by investigating identification with target category members. Participants who were primed with Blacks in comparison to Asians were faster to associate the self with Blacks. Furthermore, the inclusion of racial target categories demonstrated that the present synchronization effects even occurred with social categories for which the participants will never be members. Although our non-Black and non-Asian participants may conceivably become jocks, hippies, or overweight, they will never become Black or Asian. Furthermore, these results also indicated that factors that have been shown to influence the way we construe the self can impact this effect. When participants were exposed to stimuli related to interdependent self-construals, their self-associations changed to fit the activated social category. Notably, this pattern of findings did not occur when participants were exposed to stimuli related to independent self-construals.

One possible alternative explanation for these findings may be that initially priming Black or Asian faces increased familiarity, which in turn facilitated associations between the self and target category members. If familiarity was a primary mechanism, a main effect for social category priming would be expected in which participants exposed to the Black prime or the Asian prime would more generally increase identification with Blacks or Asians, respectively. This was not the case. Only the interaction described above between self-construal task and social category prime was significant; the main effect for social category priming was not, $F(1,78)=0.63, p=.43$. Although it may be possible to argue that familiarity effects are specific to the interdependence condition and do not occur in the independence condition, the rationale for this prediction is not clear or parsimonious. Moreover, such an explanation would be in accordance with our theorizing because it would also highlight the importance of motivations to interconnect for self-synchronization processes.

\section{General Discussion}

In 1983, Woody Allen released a pseudodocumentary about the chameleon-man, Leonard Zelig, who changed himself to fit with people in his personal surroundings. For example, when he was among doctors, Zelig transformed himself into a doctor, when he was around overweight people, he took on the identity and the form of an overweight person, when he was around Blacks or Asians, he also assumed their identities. These temporary changes to Zelig's self-concept importantly were reflected in his behaviors, his attitudes, and how he interacted with his environment. Notably,
Allen portrayed Zelig's ability to acquire identities from his environment as maladaptive, a coping mechanism by a clinical patient to alleviate a desperate need to belong. However, we suggest that this ability to synchronize the self is an automatic and nonconscious process that occurs in normal populations and is influenced not only by a need to feel interconnected but also by standard social categorization processes.

Specifically, the primary goal of the present set of studies was to examine the effect of activated social categories on the selfconcept. The results from four studies consistently demonstrated that participants assimilated distinct aspects of their self-concept to match activated target categories. In particular, the findings provide strong evidence that people modify the personality characteristics they associate with the self (Studies 1 and 2), perceptions of their physical self (Study 3), and even the extent to which they identify with outgroup social category members (Study 4) to fit activated social groups. Because of the importance of the self as an organizing concept (Leary \& Tangney, 2003), it is difficult to conceive of a process that is not inherently influenced by the way we conceive of the self. This diverse array of findings directly related to adjustments in the working self-concept therefore have significant implications for many subsequent processes related to attitudes, behaviors, emotions, and other social responses.

The present experiments also indicate that factors that influence categorization processes impact self-synchronization. Specifically, the results from Studies 2 and 3 demonstrated that contextual social goals affected which specific category was activated and the extent to which participants associated specific stereotypic traits with the self and modified their self-perceptions to match the activated category.

Recent theorizing related to mimicry, ideomotor effects, and the automatic assimilation of attitudes-although typically approached from different theoretical positions-converge on a common theme concerning why people assimilate overt responses so that they are similar to interaction partners. People modify their gestures, behaviors, and attitudes to conform to individuals in their immediate environment to pave the way for positive interpersonal relationships (Chartrand \& Bargh, 1999; Chartrand et al., 2005; Lakin et al., 2003; van Baaren et al., 2004). The present research does not challenge those conceptual frameworks or their general conclusions. However, our work does suggest that additional processes, which have not been considered directly in those other lines of study, may be involved as well. That is, although much of the previous theorizing and findings on synchronization effects are related to expressed external responses often to individual others, the present research investigated changes to the working selfconcept, which is not directly observable by others, to match activated social categories. This research, therefore, raises the question of why people modify internal representations of the self to fit large groups of people who are not in their immediate environment.

Social psychologists have long assumed that belonging to social groups is critical to human survival (Baumeister \& Leary, 1995; Gardner et al., 2000). Because people are generally attracted to others who are similar to them (Byrne, 1971), it is possible that people spontaneously change the self to become more like members of salient social groups so that they can feel interconnected with the group. Because perceiving the self as similar to the group is important for a sense of individual well-being and belongingness 
(Williams, 2007) and enhance survival likelihood by being part of a larger whole, even if this process may not be particularly relevant in a specific context, it may be socially adaptive in the long run. Notably, this more fundamental process associated with the self appears not to be based primarily in strategic impression management related to impressing other people. The responses we measured were implicit, automatically activated reflections of the self-concept in the absence of the physical presence of a member of the social category. Thus, individual differences in selfmonitoring, which relate to impression management, and characteristics related to specific individual targets such as likability or extremity may be less critical than they are for the synchronization of overt, observable behaviors, emotions, and attitudes (DeMarree et al., 2005; Hull et al., 2002; Sinclair et al., 2005). Because psychological mechanisms have evolved that dispose humans toward obligatory interdependence with groups (Schaller et al., 2010), self-synchronization to activated social categories occurs with little inducement and by default. Indeed, in the present studies, the only condition in which participants did not modify their self-concept to match the social context was when independent self-construals were primed, presumably because the need to interconnect with a larger social context was reduced by focusing on separate and distinct self-identities.

Importantly, we investigated self-synchronization processes related to a variety of different social categories and found that people change self-associations to fit categories that may not normally be considered ingroups (e.g., Blacks, the overweight). Because perceived distinctiveness from particular groups is often identified as one of the key factors in negative intergroup relations (Allport, 1954; Dovidio et al., 2004; Page-Gould, MendozaDenton, Alegre, \& Siy, 2010; Phills, Kawakami, Tabi, Nadolny, \& Inzlicht, 2011), discovering how and when people associate themselves more and less with outgroups may be critical to a better understanding of prejudice and discrimination. Indeed, recent findings suggest that increasing overlap between target groups and the self can reduce intergroup bias (Dovidio et al., 2004; Galinksy, Ku, \& Wang, 2005; Galinsky \& Moskowitz, 2000). For example, Phills et al. (2011) found that approaching Blacks significantly increased associations between the self and Blacks and that these changes to the working self-concept in turn reduced implicit prejudice against Blacks. Because the working self-concept is so fundamentally important in shaping our responses, the implications of changes to this schema for intergroup relations are considerable (Greenwald \& Banaji, 1995; Greenwald et al., 2002; Kunda, 1999).

Discovering what people associate with the self and how this changes according to the activation of social categories also has significant implications for a more comprehensive understanding of social behaviors. Although we focused on implicit associations and nonconscious processes and associations in the present study, one area for future research to explore is the impact of social category activations on more explicit processes. Although the importance of automaticity to our daily lives is undeniable (Bargh, 1997) and recent research has provided strong evidence for the link between implicit self-concepts and spontaneous attitudes (Galinsky et al., 2005; Phills et al., 2011), behaviors (DeMarree et al., 2005; S. C. Wheeler et al., 2005, 2007), and interactions (Greenwald et al., 2002), a further examination of how more deliberative self-concepts are influenced by the social context is warranted. We also recommend extending the present work on social category priming to include interactions with actual members of social groups and to incorporate measures related to category evaluations. In particular, although the present research indicates that people synchronize to the characteristics and perceptions of social categories, it would be fruitful to investigate whether people change their self-esteem to match evaluations of social categories when interacting with this group and how self-synchronization processes develop over the course of an interaction. Finally, a further examination of the boundary conditions of selfsynchronization and factors that can increase and decrease the impact of activated social categories on associations between the self and these target groups (e.g., psychological distance from the target category, construal processes, culture) is also warranted. Although it is clear from this discussion that more research is necessary and that the present research is limited in its understanding of self-synchronization processes, because of the importance of perceived self-overlap and identification with outgroups on intergroup bias (Dovidio et al., 2004; Galinksy et al., 2005; Galinsky \& Moskowitz, 2000; Page-Gould et al., 2010; Phills et al., 2011), these initial findings provide some thought-provoking ideas for gaining a better understanding of the self and perhaps even increasing harmony between social categories.

\section{References}

Aaker, J., \& Lee, A. Y. (2001). I seek pleasures, we avoid pains: The role of self regulatory goals in information processing and persuasion. Journal of Consumer Research, 28, 33-49. doi:10.1086/321946

Allport, G. W. (1954). The nature of prejudice. Reading, MA: AddisonWesley.

Bargh, J. A. (1997). The automaticity of everyday life. In R. Wyer (Ed.), Advances in social cognition (Vol. 10, pp. 1-61). Mahwah, NJ: Erlbaum.

Bargh, J. A. (2006). What have we been priming all these years? On the development mechanisms and ecology of nonconscious social behavior. European Journal of Social Psychology, 36, 147-168. doi:10.1002/ ejsp.336

Bargh, J. A., Bond, R. N., Lombardi, W. J., \& Tota, M. E. (1986). The additive nature of chronic and temporary sources of construct accessibility. Journal of Personality and Social Psychology, 50, 869-878. doi:10.1037/0022-3514.50.5.869

Bargh, J. A., Chen, M., \& Burrows, L. (1996). Automaticity of social behavior: Direct effects of trait construct and stereotype activation on action. Journal of Personality and Social Psychology, 71, 230-244. doi:10.1037/0022-3514.71.2.230

Bassili, J. N., \& Smith, M. C. (1986). On the spontaneity of trait attribution: Converging evidence for the role of cognitive strategy. Journal of Personality and Social Psychology, 50, 239-245. doi:10.1037/00223514.50.2.239

Baumeister, R. F. (Ed.). (1999). The self in social psychology. Philadelphia, PA: Psychology Press.

Baumeister, R. F., \& Leary, M. R. (1995). The need to belong: Desire for interpersonal attachments as a fundamental human motivation. Psychological Bulletin, 117, 497-529. doi:10.1037/0033-2909.117.3.497

Blair, I. V., Judd, C. M., \& Fallman, J. L. (2004). The automaticity of race and Afrocentric facial features in social judgments. Journal of Personality and Social Psychology, 87, 763-778. doi:10.1037/00223514.87.6.763

Brewer, M. B. (1988). A dual process model of impression formation. In R. S. Wyer Jr., \& T. K. Srull (Eds.), Advances in social cognition (Vol 1, pp. 1-36). Hillsdale, NJ: Erlbaum. 
Byrne, D. (1971). The attraction paradigm. New York, NY: Academic Press.

Cantor, N., Markus, H., Niedenthal, P., \& Nurius, P. (1986). On motivation and the self-concept. In R. M. Sorrentino \& E. T. Higgins (Eds.), Motivation and cognition: Foundations of social behavior (pp. 96-121). New York, NY: Guilford Press.

Chartrand, T. L., \& Bargh, J. A. (1996). Automatic activation of impression formation and memorization goals: Nonconscious goal priming reproduces effects of explicit task instructions. Journal of Personality and Social Psychology, 71, 464-478. doi:10.1037/0022-3514.71.3.464

Chartrand, T. L., \& Bargh, J. A. (1999). The chameleon effect: The perception-behavior link and social interaction. Journal of Personality and Social Psychology, 76, 893-910. doi:10.1037/0022-3514.76.6.893

Chartrand, T. L., Maddux, W. W., \& Lakin, J. L. (2005). Beyond the perception-behavior link: The ubiquitous utility and motivational moderators of nonconscious mimicry. In R. Hassin, J. S. Uleman, \& J. A. Bargh (Eds.), Unintended thought 2: The new unconscious (pp. 334361). New York, NY: Oxford University Press.

Chen, M., \& Bargh, J. A. (1997). Nonconscious behavioral confirmation processes: The self-fulfilling consequences of automatic stereotype activation. Journal of Experimental Social Psychology, 33, 541-560. doi: 10.1006/jesp.1997.1329

Cheng, C. M., \& Chartrand, T. L. (2003). Self-monitoring without awareness: Using mimicry as a nonconscious affiliation strategy. Journal of Personality and Social Psychology, 85, 1170-1179. doi:10.1037/00223514.85.6.1170

Cloutier, J. C., Mason, M. F., \& Macrae, C. N. (2005). The perceptual determinants of person construal: Reopening the social-cognitive toolbox. Journal of Personality and Social Psychology, 88, 885-894. doi: 10.1037/0022-3514.88.6.885

Cooley, C. H. (1902). Human nature and the social order. New York, NY: Charles Scribner's.

Crandall, C., Nierman, A., \& Hebl, M. (2009). Anti-fat prejudice. In T. D. Nelson (Ed.), Handbook of prejudice, stereotyping, and discrimination (pp. 469-488). New York, NY: Psychology Press.

DeMarree, K. G., Wheeler, S. C., \& Petty, R. E. (2005). Priming a new identity: Self-monitoring moderates the effects of non-self primes on self-judgments and behavior. Journal of Personality and Social Psychology, 89, 657-671. doi:10.1037/0022-3514.89.5.657

Dijksterhuis, A., \& Bargh, J. A. (2001). The perception-behavior expressway: Automatic effects of social perception and social behavior. In M. Zanna (Ed.), Advances in experimental social psychology (Vol. 30, pp. 1-40). New York, NY: Academic Press.

Dijksterhuis, A., \& van Knippenberg, A. (1998). The relation between perception and behavior or how to win a game of Trivial Pursuit. Journal of Personality and Social Psychology, 74, 865-877. doi:10.1037/00223514.74.4.865

Dovidio, J. F., Kawakami, K., Johnson, C., Johnson, B., \& Howard, A. (1997). On the nature of prejudice: Automatic and controlled processes. Journal of Experimental Social Psychology, 33, 510-540. doi:10.1006/ jesp.1997.1331

Dovidio, J. F., ten Vergert, M., Stewart, T. L., Gaertner, S. L., Johnson, J. D., Esses, V. M., . . Pearson, A. R. (2004). Perspective and prejudice: Antecedents and mediating mechanisms. Personality and Social Psychology Bulletin, 30, 1537-1549. doi:10.1177/0146167204271177

Fiske, S. T. (1998). Stereotyping, prejudice, and discrimination. In D. T. Gilbert, S. T. Fiske, \& G. Lindzey (Eds.), The handbook of social psychology (4th ed., Vol. 2, pp. 357-411). New York, NY: McGrawHill

Fiske, S. T., Lin, M. H., \& Neuberg, S. L. (1999). The Continuum Model: Ten years later. In S. Chaiken \& Y. Trope (Eds.), Dual process theories in social psychology (pp. 231-254). New York, NY: Guilford Press.

Fiske, S., \& Neuberg, S. (1990). A continuum of impression formation from category-based to individuating processes: Influences of informa- tion and motivation on attention and interpretation. In M. Zanna (Ed.), Advances in experimental social psychology (Vol. 23, pp. 1-73). New York, NY: Academic Press.

Förster, J., Liberman, N., \& Kuschel, S. (2008). The effect of global versus local processing styles on assimilation versus contrast in social judgment. Journal of Personality and Social Psychology, 94, 579-599. doi:10.1037/0022-3514.94.4.579

Gabriel, S., Kawakami, K., Bartak, C., Kang, S., \& Mann, N. (2010). Self-synchronization: Will I change to be like you when it is bad for me? Journal of Personality and Social Psychology, 98, 857-871. doi: $10.1037 / \mathrm{a} 0019272$

Gabriel, S., \& Young, A. (2011). Becoming a vampire without being bitten: The narrative collective assimilation hypothesis. Psychological Science, 22, 990-994. doi:10.1177/0956797611415541

Galinsky, A. D., Ku, G., \& Wang, C. S. (2005). Perspective-taking and self-other overlap: Fostering social bonds and facilitating social coordination. Group Processes and Intergroup Relations, 8, 109-124. doi 10.1177/1368430205051060

Galinsky, A. D., \& Moskowitz, G. B. (2000). Perspective-taking: Decreasing stereotype expression, stereotype accessibility, and in-group favoritism. Journal of Personality and Social Psychology, 78, 708-724. doi:10.1037/0022-3514.78.4.708

Galinsky, A. D., Wang, C. S., \& Ku, G. (2008). Perspective-takers behave more stereotypically. Journal of Personality and Social Psychology, 95, 404-419. doi:10.1037/0022-3514.95.2.404

Gardner, W. L., Gabriel, S., \& Lee, A. Y. (1999). "I" value freedom but "we" value relationships: Self-construal priming mirrors cultural differences in judgment. Psychological Science, 10, 321-326. doi:10.1111/ 1467-9280.00162

Gardner, W. L., Pickett, C. L., \& Brewer, M. B. (2000). Social exclusion and selective memory: How the need to belong influences memory for social events. Personality and Social Psychology Bulletin, 26, 486-496. doi: $10.1177 / 0146167200266007$

Gilbert, D. T., \& Hixon, J. G. (1991). The trouble of thinking: Activation and application of stereotypic beliefs. Journal of Personality and Social Psychology, 60, 509-517. doi:10.1037/0022-3514.60.4.509

Greenwald, A. G., \& Banaji, M. R. (1995). Implicit social cognition: Attitudes, self-esteem, and stereotypes. Psychological Review, 102, 4-27. doi:10.1037/0033-295X.102.1.4

Greenwald, A. G., \& Farnham, S. D. (2000). Using the Implicit Association Test to measure self-esteem and self-concept. Journal of Personality and Social Psychology, 79, 1022-1038. doi:10.1037/00223514.79.6.1022

Greenwald, A. G., McGhee, D. E., \& Schwartz, J. L. K. (1998). Measuring individual differences in implicit cognition: The Implicit Association Test. Journal of Personality and Social Psychology, 74, 1464-1480. doi:10.1037/0022-3514.74.6.1464

Greenwald, A. G., Nosek, B. A., \& Banaji, M. R. (2003). Understanding and using the Implicit Association Test: An improved scoring algorithm Journal of Personality and Social Psychology, 85, 197-216. doi 10.1037/0022-3514.85.2.197

Greenwald, A. G., Pickrell, J. E., \& Farnham, S. D. (2002). Implicit partisanship: Taking sides for no reason. Journal of Personality and Social Psychology, 83, 367-379. doi:10.1037/0022-3514.83.2.367

Haslam, N., Rothschild, L., \& Ernst, D. (2000). Essentialist beliefs about social categories. British Journal of Social Psychology, 39, 113-127. doi:10.1348/014466600164363

Higgins, E. T., Rholes, W. S., \& Jones, C. R. (1977). Category accessibility and impression formation. Journal of Experimental Social Psychology, 13, 141-154. doi:10.1016/S0022-1031(77)80007-3

Hong, Y. Y., Morris, M., Chiu, C. Y., \& Benet-Martínez, V. (2000) Multicultural minds: A dynamic constructivist approach to culture and cognition. American Psychologist, 55, 709-720. doi:10.1037/0003066X.55.7.709 
Hsee, C. K., Hatfield, E., Carlson, J., \& Chemtob, C. (1990). The effect of power on susceptibility to emotional contagion. Cognition \& Emotion, 4, 327-340. doi:10.1080/02699939008408081

Hull, J. G., Slone, L. B., Meteyer, K. B., \& Matthews, A. R. (2002). The nonconsciousness of self-consciousness. Journal of Personality and Social Psychology, 83, 406-424. doi:10.1037/0022-3514.83.2.406

James, W. (1890). The principles of psychology. New York, NY: Holt. doi:10.1037/11059-000

Kawakami, K., Dovidio, J. F., \& Dijksterhuis, A. (2003). Effect of social category priming on personal attitudes. Psychological Science, 14, 315319. doi:10.1111/1467-9280.14451

Kawakami, K., Steele, J. R., Cifa, C., Phills, C. E., \& Dovidio, J. F. (2008). Approaching math increases math $=$ me, math $=$ pleasant. Journal of Experimental Social Psychology, 44, 818-825. doi:10.1016/j.jesp.2007.07.009

Kawakami, K., Young, H., \& Dovidio, J. F. (2002). Automatic stereotyping: Category, trait, and behavioral activations. Personality and Social Psychology Bulletin, 28, 3-15. doi:10.1177/0146167202281001

Kitayama, S., \& Markus, H. R. (1995). Construal of self as cultural frame: Implications for internationalizing psychology. In N. R. Goldberger \& J. B. Veroff (Eds.), The culture and psychology reader (pp. 366-383). New York: New York University Press.

Kunda, Z. (1999). Social cognition: Making sense of people. Cambridge, MA: MIT Press.

Kunda, Z., \& Spencer, S. J. (2003). When do stereotypes come to mind and when do they color judgment? A goal-based theoretical framework for stereotype activation and application. Psychological Bulletin, 129, 522544. doi:10.1037/0033-2909.129.4.522

Lakin, J. L., \& Chartrand, T. L. (2003). Using nonconscious behavioral mimicry to create affiliation and rapport. Psychological Science, 14, 334-339. doi:10.1111/1467-9280.14481

Lakin, J. L., Jefferis, V. E., Cheng, C. M., \& Chartrand, T. L. (2003). The chameleon effect as social glue: Evidence for the evolutionary significance of nonconscious mimicry. Journal of Nonverbal Behavior, 27, 145-162. doi:10.1023/A:1025389814290

Leary, M. R., \& Tangney, J. P. (2003). The self as an organizing construct in the self and behavioral sciences. In M. R. Leary \& J. P. Tangney (Eds.), Handbook of self and identity (pp. 3-14). New York, NY: Guilford Press.

Lee, S., Lee, A. J., \& Kern, M. C. (2011). Viewing time through the lens of the self: The fit effect of self-construal and temporal distance on task perception. European Journal of Social Psychology, 41, 191-200. doi: 10.1002/ejsp.765

Leyens, J.-P., Desert, M., Croizet, J.-C., \& Darcis, C. (2000). Stereotype threat: Are lower status and history of stigmatization preconditions of stereotype threat. Personality and Social Psychology Bulletin, 26, 11891199. doi: $10.1177 / 0146167200262002$

Livingston, R. W., \& Brewer, M. B. (2002). What are we really priming? Cue-based versus category-based processing of facial stimuli. Journal of Personality and Social Psychology, 82, 5-18. doi:10.1037/00223514.82.1.5

Lowery, B. S., Hardin, C. D., \& Sinclair, S. (2001). Social influence effects on automatic racial prejudice. Journal of Personality and Social Psychology, 81, 842-855. doi:10.1037/0022-3514.81.5.842

Macrae, C., Bodenhausen, G., \& Milne, A. (1995). The dissection of selection in person perception: Inhibitory processes in social stereotyping. Journal of Personality and Social Psychology, 69, 397-407. doi: 10.1037/0022-3514.69.3.397

Macrae, C. N., Quinn, K. A., Mason, M. F., \& Quadflieg, S. (2005). Understanding others: The face and person construal. Journal of Personality and Social Psychology, 89, 686-695. doi:10.1037/00223514.89.5.686

Markus, H. R., \& Kunda, Z. (1986). Stability and malleability of the self-concept. Journal of Personality and Social Psychology, 51, $858-$ 866. doi:10.1037/0022-3514.51.4.858

Markus, H. R., \& Nurius, P. (1986). Possible selves. American Psychologist, 41, 954-969. doi:10.1037/0003-066X.41.9.954

Maslow, A. H. (1968). Toward a psychology of being. New York, NY: Van Nostrand.

Mead, G. H. (1934). Mind, self, and society. Chicago, IL: University of Chicago Press.

Mills, J. (2000). Graphic Image Altering Program (GIAP). Location: Publisher.

Neumann, R., \& Strack, F. (2000). Approach and avoidance: The influence of proprioceptive and exteroceptive cues on encoding of affective information. Journal of Personality and Social Psychology, 79, 39-48. doi:10.1037/0022-3514.79.1.39

Nosek, B. A., Banaji, M. R., \& Greenwald, A. G. (2002). Math = male, $\mathrm{me}=$ female, therefore math $\neq$ me. Journal of Personality and Social Psychology, 83, 44-59. doi:10.1037/0022-3514.83.1.44

Page-Gould, E., Mendoza-Denton, R., Alegre, J. M., \& Siy, J. O. (2010) Understanding the impact of cross-group friendship on interactions with novel outgroup members. Journal of Personality and Social Psychology, 98, 775-793. doi:10.1037/a0017880

Phills, C. E., Kawakami, K., Tabi, E., Nadolny, D., \& Inzlicht, M. (2011). Mind the gap: Increasing associations between the self and Blacks with approach behaviors. Journal of Personality and Social Psychology, 100, 197-210. doi:10.1037/a0022159

Pinter, B., \& Greenwald, A. G. (2005). Clarifying the role of the "other" category in the self-esteem IAT. Experimental Psychology, 52, 74-79. doi:10.1027/1618-3169.52.1.74

Rothbart, M., \& Taylor, M. (1992). Category labels and social reality: Do we view social categories as natural kinds? In G. R. Semin \& K. Fiedler (Eds.), Language, interaction, and social cognition (pp. 11-36). Newbury Park, CA: Sage.

Schaller, M., Conway, L. C., \& Peavy, K. M. (2010). Evolutionary processes. In J. F. Dovidio, M. Hewstone, P. Glick, \& V. M. Esses (Eds.), Handbook of prejudice, stereotyping, and discrimination (pp. 81-96). London, England: Sage.

Schubert, T., \& Häfner, M. (2003). Contrast from social stereotypes in automatic behavior. Journal of Experimental Social Psychology, 39, 577-584. doi:10.1016/S0022-1031(03)00034-9

Showers, C. J., \& Zeigler-Hill, V. (2003). Organization of self-knowledge: Features, functions, and flexibility. In M. R. Leary \& J. Tangney (Eds.), Handbook of self and identity (pp. 47-67). New York, NY: Guilford Press.

Sinclair, S., Lowery, B. S., Hardin, C. D., \& Colangelo, A. (2005). The social tuning of automatic ethnic attitudes: The role of affiliative motivation. Journal of Personality and Social Psychology, 89, 583-592. doi:10.1037/0022-3514.89.4.583

Srull, T. K., \& Wyer, R. S. (1979). The role of category accessibility in the interpretation of information about persons: Some determinants and implications. Journal of Personality and Social Psychology, 37, 16601672. doi:10.1037/0022-3514.37.10.1660

Stangor, C., \& Lange, J. E. (1994). Mental representations of social groups: Advances in understanding stereotypes and stereotyping. In M. Zanna (Ed.), Advances in experimental social psychology (Vol. 25, pp. $357-$ 416). New York, NY: Academic Press.

Stangor, C., Lynch, L., Duan, C., \& Glass, B. (1992). Categorization of individuals on the basis of multiple social features. Journal of Personality and Social Psychology, 62, 207-218. doi:10.1037/00223514.62.2.207

Stapel, D. A., \& Blanton, H. (2004). From seeing to being: Subliminal social comparisons affect implicit and explicit self-evaluations. Journal of Personality and Social Psychology, 87, 468-481. doi:10.1037/00223514.87.4.468

Steele, J. R., \& Ambady, N. (2006). "Math is hard!" The effect of gender 
priming on women's attitudes. Journal of Experimental Social Psychology, 42, 428-436. doi:10.1016/j.jesp.2005.06.003

Trafimow, D., Triandis, H. C., \& Goto, S. G. (1991). Some tests of the distinction between the private self and the collective self. Journal of Personality and Social Psychology, 60, 649-655. doi:10.1037/00223514.60.5.649

van Baaren, R. B., Holland, R. W., Kawakami, K., \& van Knippenberg, A. (2004). Mimicry and prosocial behavior. Psychological Science, 15, 71-74. doi:10.1111/j.0963-7214.2004.01501012.x

van Baaren, R. B., Holland, R. W., Steenaert, B., \& van Knippenberg, A. (2003). Mimicry for money: Behavioral consequences of imitation. Journal of Experimental Social Psychology, 39, 393-398. doi:10.1016/ S0022-1031(03)00014-3

Wheeler, M. E., \& Fiske, S. T. (2005). Controlling racial prejudice: Social-cognitive goals affect amygdala and stereotype activation. Psychological Science, 16, 56-63. doi:10.1111/j.0956-7976.2005.00780.x

Wheeler, S. C., DeMarree, K. G., \& Petty, R. E. (2005). The roles of the self in priming-to-behavior effects. In A. Tesser, J. V. Wood, \& D. A. Stapel (Eds.), On building, defending, and regulating the self: A psychological perspective (pp. 245-271). New York, NY: Psychology Press.
Wheeler, S. C., DeMarree, K. G., \& Petty, R. E. (2007). Understanding the role of the self in prime-to-behavior effects: The Active-Self Account. Personality and Social Psychology Bulletin, 11, 234-261. doi:10.1177/ 1088868307302223

Wheeler, S. C., \& Petty, R. E. (2001). The effects of stereotype activation on behavior: A review of possible mechanisms. Psychological Bulletin, 127, 797-826. doi:10.1037/0033-2909.127.6.797

Williams, K. D. (2007). Ostracism. Annual Review of Psychology, 58 425-452. doi:10.1146/annurev.psych.58.110405.085641

Yzerbyt, V., Corneille, O., \& Estrada, C. (2001). The interlay of subjective essentialism and entitativity in the formation of stereotypes. Personality and Social Psychology Review, 5, 141-155. doi:10.1207/ S15327957PSPR0502_5

Zárate, M. A., \& Smith, E. R. (1990). Person categorization and stereotyping. Social Cognition, 8, 161-185. doi:10.1521/soco.1990.8.2.161

Received October 16, 2010

Revision received July 11, 2011

Accepted August 26, 2011

\section{E-Mail Notification of Your Latest Issue Online!}

Would you like to know when the next issue of your favorite APA journal will be available online? This service is now available to you. Sign up at http://notify.apa.org/ and you will be notified by e-mail when issues of interest to you become available! 